\title{
GESTÃO AMBIENTAL NO IFRN: IMPLEMENTAÇÃO DE UMA POLÍTICA AMBIENTAL CONSIDERANDO O PAPEL DAS INSTITUIÇÕES DE ENSINO NO DESENVOLVIMENTO SUSTENTÁVEL
}

\author{
JORGE HENRIQUE BEZERRA ANDRADE \\ Tecnólogo em Meio Ambiental (IFRN), Acadêmico Concluinte de Administração \\ (UFRN), pesquisador da área de gestão organizacional e ambiental. \\ E-mail.jorgecefet@yahoo.com.br
}

HANDSON CLAUDIO DIAS PIMENTA

Engenheiro de Produção (UFRN), Mestre em Engenharia de Produção (UFRN), Tecnólogo em Meio Ambiente (IFRN), Coordenador do Núcleo de Estudos em Sustentabilidade

Empresarial do IFRN.

E-mail. handson@cefetrn.br

\begin{abstract}
RESUMO
A preocupação com o desenvolvimento sustentável e ações de gestão ambiental vem ganhando um espaço crescente nas Instituições de Ensino Superior. O Instituto Federal de Educação, Ciência e Tecnologia do Rio Grande do Norte - IFRN inserido nesse contexto passou, a reunir esforços e a direcionar ações para possibilitar a sustentabilidade de suas atividades. O presente artigo tem como objetivo geral propor uma política Ambiental para a unidade sede do IFRN refletindo sobre o papel das Instituições de Ensino no Desenvolvimento Sustentável. Trata-se de uma pesquisa-ação que analisou a instituição sob uma perspectiva holística adotando a abordagem de inputs, elementos de processo e outputs, ponto de partida para a sistematização das ações necessárias. Na perspectiva do ambiente interno, foi realizado um levantamento sobre todos os programas, processos e projetos relacionados ao escopo ambiental. A política foi construída a partir da participação efetiva da comissão de gestão ambiental da unidade sede e contempla sua visão e comprometimento em relação das ações de gestão ambiental da instituição. Ela contém 08 diretrizes que tratam respectivamente de: Controle Eficiente de Água e Energia, Uso Racional de Materiais de Consumo, Gerenciamento de Resíduos sólidos, Gerenciamento das Obras Civis, Gerenciamento de Áreas Verdes, Educação Ambiental, Suporte de Recursos e Requisitos Legais.
\end{abstract}

PALAVRAS CHAVE: Política Ambiental, Gestão Ambiental, Instituição de Ensino, Desenvolvimento Sustentável. 


\title{
ENVIRONMENTAL MANAGEMENT AT IFRN: IMPLEMENTATION OF AN ENVIRONMENTAL POLICY CONSIDERING THE EDUCATION INSTITUTIONS ROLE TOWARDS SUSTAINABLE DEVELOPMENT
}

\begin{abstract}
The concern with the sustainable development and the environmental management actions has been gaining a growing area in the Higher Education Institutions. The Federal Institute of Education, Science and Technology of Rio Grande do Norte - IFRN inserted in that context, began to direct efforts in order to facilitate the sustainability of their activities. This article aims to propose a environmental policy for the IFRN reflecting on the role of educational institutions in Sustainable Development. It is an action research which examined the institution in a holistic perspective by adopting the inputs-process-outputs approach. In view of the internal environment, a survey was conducted on all programs, processes and projects related to environmental scope. The policy has been built from the effective participation of the environmental management committee and includes their vision and commitment in respect of the environmental management actions of the institution. It contains 08 guidelines dealing respectively: water and energy effective control, rational materials use, waste management, civil works management, green areas management, environmental education, support resources and legal requirements.
\end{abstract}

KEY WORDS: Environmental Policy, Environmental Management, Education Institutions, Sustainable Development. 


\section{GESTÃO AMBIENTAL NO IFRN: IMPLEMENTAÇÃO DE UMA POLÍTICA AMBIENTAL CONSIDERANDO O PAPEL DAS INSTITUIÇÕES DE ENSINO NO DESENVOLVIMENTO SUSTENTÁVEL}

\section{INTRODUÇÃO}

Quando uma organização decide incorporar os princípios do desenvolvimento sustentável nas suas atividade, produtos e serviços observam-se modificações em todos os níveis e estruturas organizacionais, ou seja do nível operacional ao estratégico. Nesse sentido, a temática ambiental ganha papel de destaque no planejamento, implementação e controle dos planos, programas, processos e técnicas para prevenção da poluição e a melhoria continua do desempenho ambiental de organizações.

Na tentativa de sistematizar e orientar as ações ambientais neste contexto empresarial, a ISO - organização internacional de padronização, com sede na Suíça - elaborou uma série norteadora com inspiração nos sistemas de gestão da qualidade, fundamentadas no chamado ciclo PDCA - planejar, executar, verificar e agir (Plan, Do, Check, Act, em inglês). Assim, merece destaque a NBR ABNT ISO 14001:2004, norma técnica que especifica os requisitos de um sistema de gestão ambiental.

Ao utilizar a abordagem de processos através da utilização do Ciclo PDCA - os responsáveis pelas decisões de uma organização passam a direcionar suas atividades com o intuito de atender aos requisitos da ISO 14001 incluindo o processo inicial de elaboração da Política Ambiental que merece destaque e deve ser elaborado com base nas especificações e recomendações desta norma.

Segundo Moreira (2001) a política ambiental é uma espécie de carta de intenção e pode ser considerada a bússola do sistema, pois contém as diretrizes que devem norteá-lo servindo de base para a definição dos objetivos e metas. Nesse sentido, o estabelecimento de uma política ambiental é fundamental para conceder transparência aos processos de gestão junto aos diversos stakeholders de uma organização e evitar ações pontuais e estanques que quando isoladas de nada contribuem para a sustentabilidade organizacional.

Dessa forma, o presente estudo tem como objetivo propor uma política ambiental para O campus central do Instituto Federal de Educação, Ciência e Tecnologia do Rio Grande do Norte - IFRN refletindo sobre o papel das Instituições de Ensino no Desenvolvimento Sustentável. Como objetivos específicos destacam-se: efetuar uma avaliação ambiental inicial da Instituição e definir as diretrizes que devem compor a política ambiental.

Para atingir os objetivos que guiam esse esforço, o estudo em tela procurou, no primeiro momento, sistematizar informações que auxiliassem na reflexão do papel das Instituições de Ensino no Desenvolvimento Sustentável. Em seguida são apresentados os aportes teóricos que subsidiaram o entendimento técnico da Política Ambiental. No segundo momento é destacado os procedimentos metodológicos adotados para na seqüência expor os resultados e discussões e as considerações finais sobre o estudo. 


\section{REVISÃO DE LITERATURA}

\section{O Papel das IES no Desenvolvimento Sustentável}

Quando se fala dos problemas ambientais na maioria das vezes tenta-se simplificar os debates em uma relação linear de causa e efeito. Contudo, o contexto desta temática é muito mais complexo. O homem na sua relação com a natureza procura a satisfação das necessidades e desejos em uma abordagem capitalista que reduz o meio ambiente a uma fonte inesgotável de recursos. Tal visão provoca uma crise de valores em que o ter sobrepuja o ser, podendo esta ser contornada por meio da educação.

Nesse sentido, a educação ambiental surge como uma grande ferramenta para a solução dos problemas do meio ambiente, sendo necessário um esforço sistemático para reverter, impedir ou minimizar os agraves ambientais, os quais depende da formação ou mudança de valores individuais e sociais que devem expressar-se em ações que levem à transformações da sociedade.

$\mathrm{Na}$ perspectiva desse processo educacional, é possível compreender os desafios e descobrir as saídas para os impasses da atualidade. O equilíbrio ambiental depende de ações concretas motivadas pela formação de um consciente coletivo. Nesse sentido, emerge um novo paradigma que convoca à todos para ação-reflexão-ação em prol da sustentabilidade.

É salutar mencionar que o ambiente acadêmico merece destaque pela sua busca por este equilíbrio ambiental e para isso, conta com as estratégias da pedagogia ambiental. Estas estratégias, de acordo com Leff (2003), implica no enlaçamento de práticas, identidades e saberes, de conhecimentos científicos e saberes popular; é a prática no qual o ser (individual e coletivo) se forja no saber.

É esse saber que possibilita uma mudança de valores e de atitudes, fundamental para o exercício da sustentabilidade ambiental. Sabe-se que o ambiente acadêmico não é o único responsável por tal mudança. Contudo, ele assume papel estratégico nesse processo.

Nesse momento, enfatiza-se o pensamento de Nalini (2003, p. 29):

“A universidade, instituição a refletir uma concepção enciclopédica do
conhecimento, precisa obedecer ao principio da indissociabilidade entre
pesquisa, ensino e extensão. A ecologia favorece uma singular vivencia
dessa tríade. O aprendizado é o convite a incursão de um universo de
conhecimento. A pesquisa favorece uma compreensão mais completa do
meio. O trabalho de extensão permitirá redirecionar a intervenção
humana sobre o ambiente, hoje prioritariamente destrutiva”

Essa compreensão mais completa do meio mencionada por Nalini, é fundamental para a construção de novas mentalidades e habilidades abrindo o caminho para o futuro sustentável. O autor ainda afirma que não há um saber ambiental definitivo cuja aquisição se possa fazer de imediato. Todas as metodologias e estratégias estão abertas à criatividade. Segundo Nalini é essencial centrar-se sobre a valorização do ambiente. Para 
ele, os valores ambientais se induzem por diferentes meios (e não só dentro dos processos educativos formais), produzindo efeitos educativos.

São esses valores ambientais que devem ser levados em consideração nos processos decisórios da vida em sociedade. Os mais capacitados e responsáveis pelas decisões que causam impactos ambientais significativos quase sempre recebem formação nas IES. No entanto, ainda são poucas as práticas observadas nessas instituições, as quais têm o papel de qualificar e conscientizar os tomadores de decisões do amanhã (TAUCHEN; BRANDLI 2006).

Ainda em relação a Tauchen e Brandli (2006) o papel de destaque assumido pelas IES no processo de desenvolvimento, na preparação de estudantes e fornecimento de informações e conhecimentos pode e devem ser utilizados também para construir o desenvolvimento de uma sociedade justa. Os autores afirmam que para isso acontecer é indispensável que essas organizações assumam um processo de conscientização em todos os seus níveis, atingindo professores, funcionários e alunos.

É importante destacar que esse processo de conscientização deve contemplar o saber ecológico que segundo Capra (2003, p. 37):

\footnotetext{
"Será o papel mais importante da educação do século 21. A alfabetização ecológica deve se tornar um requisito essencial para políticos, empresários e profissionais de todos os ramos, e deveria ser uma preocupação central da educação em todos os níveis - do ensino fundamental e médio até as universidades e os cursos continuados e de treinamento de profissionais”.
}

No caso das universidades é imprescindível qualificar os cursos de graduação e pósgraduação no que se refere ao meio ambiente. Segundo Tauchen et al (2005, p. 05):

“O desenvolvimento sustentável procura nas Instituições de Ensino Superior (IES) um agente especialmente equipado para liderar o caminho, pois a sua missão é o ensino e a formação dos tomadores de decisão do futuro, ou dos profissionais mais capacitados para a tomada de decisão”.

Desta forma, observa-se o papel relevante das instituições de ensino superior na promoção do desenvolvimento sustentável, seja pelo processo de ensino, seja pela pesquisa e extensão, direcionados para o atendimento das necessidades atuais da humanidade e uso dos recursos naturais dentro da capacidade de suporte, além de não comprometer a habilidade da futuras gerações em atender suas próprias necessidades. O IFRN se enquadra neste contesto, pela formação de profissionais das diversas áreas dos saberes, incluindo também suas pesquisas e ações voltadas para comunidade.

\section{Política Ambiental}

Neste tópico serão apresentados alguns conceitos, além de uma discussão em cima das especificações e recomendações da ISO 14001:2004 para elaboração e implementação de uma política ambiental.

A política ambiental consiste em um conjunto consistente de princípios doutrinários que conformam as aspirações sociais e ou governamentais no que concerne à regulamentação ou modificação no uso, controle, proteção e conservação do ambiente (SEIFFERT, 2007). 
Segundo Cajazeira (1998) a formação da política ambiental vem sendo historicamente um item normativo ainda delegado ao caráter empírico das organizações. Geralmente forma-se um grupo de pessoas que, baseadas em outras empresas, elaboram um texto quase sempre formado por frases de efeito que, no entanto, pouco tem a ver com as práticas e anseios da organização e dos organismos envolvidos.

Para Moreira (2001) a política ambiental é uma espécie de carta de intenção e pode ser considerada a bússola do sistema, pois contem as diretrizes que devem norteá-lo, servindo de base para a definição e revisão de objetivos e metas.

Na estruturação de um Sistema de Gestão Ambiental ${ }^{1}$ para uma organização, a política ambiental visa estabelece um senso de orientação das ações ambientais de uma organização. Ela determina o objetivo global no tocante ao nível global de responsabilidade e desempenho ambiental requerido da organização, com referência ao quais todas as ações subseqüentes serão julgadas, sendo desta forma a força motriz para a implementação e aprimoramento do sistema da gestão ambiental de uma organização, permitindo que seu desempenho ambiental seja mantido e potencialmente aperfeiçoado.

Assim, a direção da empresa deve elaborar uma política ambiental que represente seus produtos e serviços, que seja divulgada entre os funcionários e a comunidade. Deve demonstrar também que está comprometida com o cumprimento dessa política, além de obter o cumprimento legal e buscar o melhoramento contínuo do desempenho ambiental da empresa.

Em linhas gerais, a ISO 14001:2004 especifica que:

A alta administração deve definir a política ambiental da organização e assegurar que ela:

- Seja apropriada à natureza, escala e impactos ambientais de suas atividades, produtos ou serviços;

- Inclua o comprometimento com a melhoria contínua e com a prevenção da poluição;

- Inclua o comprometimento com o atendimento à legislação e normas ambientais aplicáveis, e demais requisitos subscritos pela organização;

- Forneça a estrutura para o estabelecimento e revisão dos objetivos e metas ambientais;

- Esteja disponível para o público.

Assim, é possível observar que a política ambiental deve explicitar todos os princípios e compromissos assumidos pela organização no intuito de sua melhor relação possível com o meio ambiente, embasada na legislação ambiental vigente. Definida pela alta direção, o seu objetivo maior deve ser o de acompanhar a performance ambiental de forma contínua, levando em conta o seu diagnóstico ambiental atual (onde estamos) e as metas a serem alcançadas (aonde queremos chegar). Uma vez definida, a política ambiental deve ser divulgada a seus acionistas, empregados, clientes, fornecedores e comunidade em geral, sendo fundamental o estreitamento de relações com a comunidade do entorno e com segmentos da sociedade envolvidos e interessados, evitando ao máximo, questionamentos

\footnotetext{
1 De acordo com a ISO 14001 um SGA consiste na parte de um sistema da gestão de uma organização utilizada para desenvolver e implementar sua política ambiental, para gerenciar seus aspectos ambientais e para estabelecer e atingir seus objetivos ambientais, incluindo uma estrutura organizacional, atividades de planejamento, responsabilidades, práticas, procedimentos, processos e recursos.
} 
do desempenho ambiental que possam ficar sem resposta eficiente, não permitindo desta forma o descrédito do sistema de gestão ambiental (VITERBO, 1998).

Destaca-se ainda a necessidade de inclusão de três itens no texto da política: o comprometimento com a busca da melhoria contínua e a prevenção da poluição, além do o comprometimento com o atendimento à legislação e normas ambientais aplicáveis, e demais requisitos subscritos pela organização.

Nessa perspectiva, uma política ambiental é um ponto de partida para começar a desenvolver um SGA e, também é um ponto de referência para a melhoria. A política deve ser regulamentada, avaliada e modificada, quando necessária, para refletir as mudanças nas prioridades ambientais.

Segundo Tauchen e Brandli (2006) nas IES, a política deve funcionar de duas maneiras: (1) dentro das IES (faculdade, estudantes, administrativo, operações, manutenção, planta física, e os empregados da faculdade), a política deve focalizar a atenção nas edições ambientais associadas com as atividades e os serviços; e (2) fora da IES (reguladores e comunidade) a política é um compromisso público e deve dirigir-se a questões ambientais e melhorar continuamente o seu desempenho ambiental.

Tauchen (2006) durante o desenvolvimento da pesquisa, elaborou a Política Ambiental da Faculdade de Horizontina, localizada no Rio Grande do Sul, sendo ela:

\begin{abstract}
“A Política Ambiental da FAHOR - Faculdade Horizontina visa promover os princípios do desenvolvimento sustentável junto aos acadêmicos, docentes, funcionários e à sociedade, através de iniciativas voltadas à preservação do meio ambiente e em conformidade com a legislação ambiental, buscando a melhoria contínua” (FAHOR, 2006).
\end{abstract}

É importante destacar que muitas organizações elaboram suas políticas sem deixar claro quais serão as reais intenções em relação ao desempenho ambiental. Muitas, como é o caso da política supracitada, recorrem a frases de efeito como: "promover os princípios do desenvolvimento sustentável” e na maioria das vezes não consideram as informações extraídas de uma avaliação ambiental inicial.

Nesse momento, cabe ressaltar as recomendações de Seiffert (2007) ao mencionar que se devem evitar no conteúdo da política certos tipos de frases que, embora possam, aparentemente, conferir mais impacto ao texto, também podem conferir alto grau de generalismo e falta de objetividade. A autora fornece exemplos de expressões que podem comprometer a certificação de um SGA conforme negrito abaixo - é importante destacar que as empresas nunca devem declarar o que não podem cumprir.

- a empresa busca alcançar o desenvolvimento sustentável;

- educar e treinar todos os funcionários e comunidades vizinhas;

- padrão de excelência mundial;

- buscar o atendimento a todas as expectativas de nossos clientes;

- utilizar a melhor tecnologia disponível.

Além disso, recomenda-se que a política ambiental seja suficientemente clara para seu entendimento pelas partes interessadas internas e externas e que ela seja periodicamente analisada e revisada, para refletir as mudanças nas condições e informações e seja 
claramente identificável e reflita sua natureza singular, escala e os impactos ambientais das atividades, produtos e serviços, dentro do escopo definido do sistema da gestão ambiental.

Por fim, é salutar destacar que uma política ambiental nunca será definitiva. Ela é preparada ao inicio de um processo de implementação de um SGA, no entanto, gradualmente ocorrem muitas modificações na empresa, decorrentes dessa própria política e das atividades do plano de ação. Assim, com o tempo, a política ficará superada, necessitando de uma revisão e atualização, quando serão colocadas novas metas para um período seguinte, por exemplo, em um novo ciclo PDCA (MOURA, 2002).

\section{METODOLOGIA DA PESQUISA}

\section{Problema}

Gil (2007) define problema em um projeto de pesquisa como uma situação não resolvida que é objeto de discussão. Para Roesch (2005), no contexto de um projeto de prática profissional, um problema é uma situação não resolvida, mas também pode ser a identificação de oportunidades até então não percebidas pela organização.

Neste caso, o problema que desencadeou este estudo foi: Quais eixos temáticos devem compor a Política Ambiental do campus central do IFRN, tendo como base o desempenho ambiental da instituição, os requisitos da ISO 14001 e as reflexões sobre desenvolvimento sustentável e gestão ambiental?

\section{Pesquisa e Metodologia}

Com base nos procedimentos técnicos, esta pesquisa pode ser classificada com uma pesquisa-ação, que pode ser definida, segundo Thiollent, citado por Gil (2007) como:

\footnotetext{
“... um tipo de pesquisa com base empírica que é concebida e realizada em estreita associação com uma ação ou com a resolução de um problema coletivo e no qual os pesquisadores e participantes representativos da situação ou do problema estão envolvidos de modo cooperativo ou participativo.”
}

O planejamento da pesquisa-ação difere de outros tipos de pesquisa, não só pela flexibilidade, mas também porque envolve a ação dos pesquisadores e dos grupos interessados, o que pode ocorrer em qualquer momento da pesquisa, dificultando seu planejamento com bases em fases ordenadas temporalmente.

Portanto, no decorrer deste estudo, apresentam-se alguns conjuntos de ações que, segundo Gil (2007), embora não ordenados no tempo, podem ser considerados como etapas da pesquisa-ação. São eles:

- Fase exploratória: tem como objetivo determinar o campo de investigação e as expectativas dos interessados. Isso implica no reconhecimento visual do local, a consulta de documentos diversos e a discussão com as partes envolvidas. Nessa etapa vislumbrouse a oportunidade de institucionalizar a variável ambiental no IFRN por meio da elaboração de uma minuta da política (elemento textual) e das pesquisas subjacentes 
(subsídios para elaboração da parte textual).

- Formulação do problema: procura-se garantir que o problema seja definido com precisão e que contemple um objetivo prático, justificando a participação dos interessados. No caso em questão - conforme mencionado: Quais eixos temáticos devem compor a Política Ambiental do campus central do IFRN, tendo como base o desempenho ambiental da instituição, os requisitos da ISO 14001 e as reflexões sobre desenvolvimento sustentável e gestão ambiental?

- Seleção da amostra e coleta de dados: o objetivo desta etapa é delimitar o universo da pesquisa e os elementos que serão pesquisados. Diversas técnicas podem ser adotadas para a coleta de dados, porém, neste estudo, utilizou-se à entrevista com aplicação de questionários. O questionário foi estruturado sob uma perspectiva holística adotando uma abordagem de inputs e outputs, os seja, identificando os aspectos ambientais ${ }^{2}$ de entrada e os aspectos de saída da organização, além dos programas e projetos de gestão ambiental existentes. Assim, os temas avaliados foram: uso da água, energia elétrica, compra de materiais e contratação de serviços, obras e reformas, educação ambiental, programas de gestão, requisitos legais, resíduos sólidos, geração de emissões atmosféricas, efluentes líquidos, ruídos vibrações e odores, área verde e programas de extensão.

- Fase de ação: nesta fase, indicam-se os objetivos que se pretende atingir; a população a ser beneficiada; a identificação de oportunidades de melhoria e a incorporação de sugestões. Nesse sentido, a construção da política considerou os resultados da avaliação ambiental inicial do IFRN e procurou espaços de construção participativa, incluindo treinamento sobre o processo de elaboração da política ambiental com a Comissão de Gestão Ambiental visando o envolvimento e as sugestões dos membros; Realização de seminário para professores e alunos da unidade visando. Considerando os dados técnicos obtidos na avaliação ambiental inicial e as discussões internas sobre a política foi levada para direção do campus central uma proposta de minuta.

- Fase de Avaliação: esta fase teve como objetivo a discussão em torno dos dados obtidos, de onde decorre a interpretação de seus resultados e a avaliação do alcance dos objetivos propostos. Dessa forma, após as reflexões finais foi elaborado o Capítulo Resultados e Discussões contemplando as informações referentes à Política Ambiental e a Caracterização Ambiental do campus central do IFRN.

O processo de elaboração da política ambiental pode ser representado pela figura 1:

\footnotetext{
${ }^{2}$ Um aspecto ambiental é um elemento das atividades ou produtos ou serviços de uma organização que pode interagir com o meio ambiente podendo causar impactos ambientais, ou seja modificações no meio ambiente, de forma adversa ou benéfica (ISO 14001). Os aspectos de entrada estão relacionados ao consumo de matérias-primas, água, energia e insumos. Já os aspectos de saída relacionam-se a emissão de poluentes, tais como geração de resíduos, efluentes líquidos, emissões atmosféricas, ruído, calor, vibração.
} 


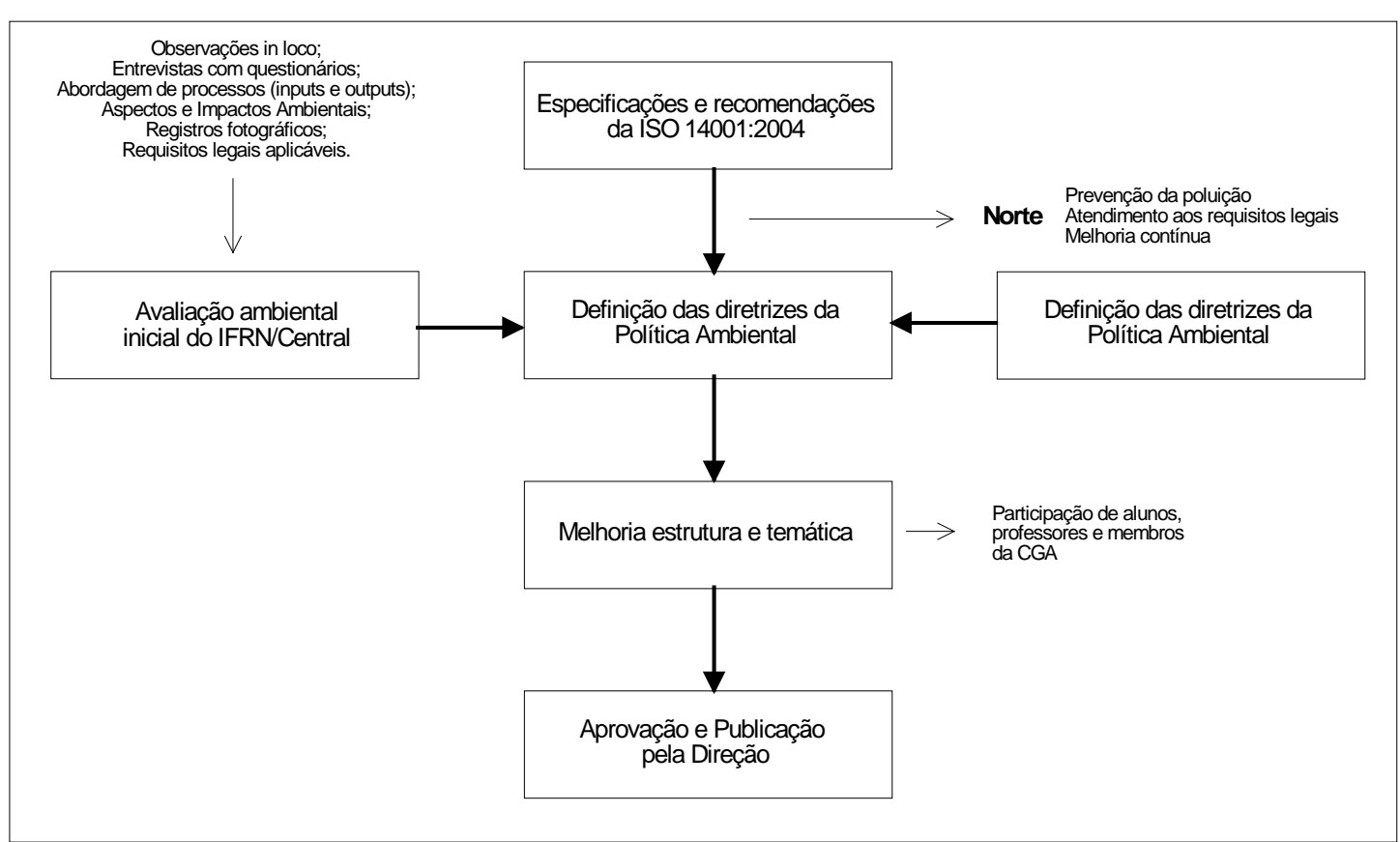

Figura 1: Etapas para elaboração da política

\section{RESULTADOS E DISCUSSÕES}

Os resultados apresentados nesse momento retratam a avaliação ambiental inicial e a política ambiental do IFRN. Para efeito desse artigo somente serão relatados os aspectos ambientais considerados prioritários e que, portanto, foram contemplados no texto da política.

\section{Diagnóstico Ambiental Inicial do IFRN/ Campus Central}

As Instituições de Ensino Superior (IES), como as empresas, apresentam numerosos aspectos ambientais relacionados com as suas atividades cotidianas, com os seus respectivos impactos ambientais. Assim, observa-se a geração de resíduos sólidos, efluentes líquidos, consumo de recursos naturais, etc. Para realizar a caracterização ambiental, o IFRN foi analisado através da abordagem de inputs e outputs - sintetizada pela figura 2. Os tópicos a seguir apresentarão o panorama que subsidiou a elaboração da Política Ambiental. 


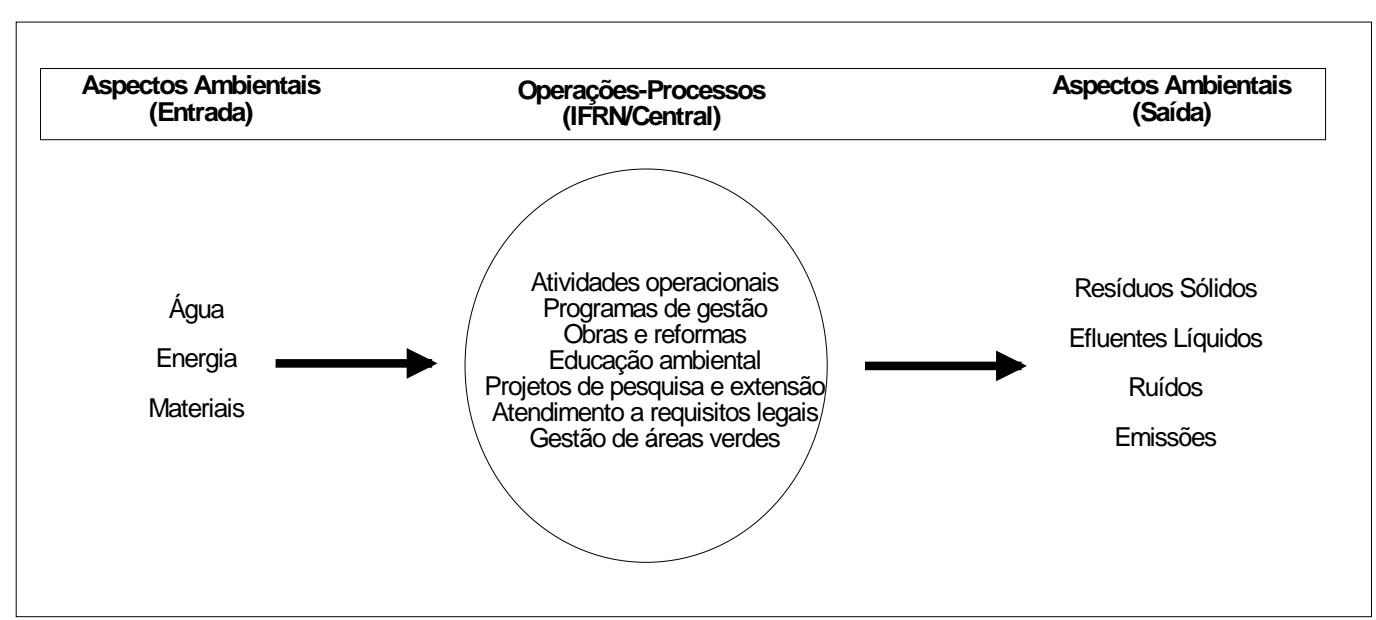

Figura 2: Visão de inputs e outputs do IFRN

\section{Uso da Água e Geração de Efluentes}

A água é um dos recursos naturais mais importantes existentes na natureza, o IFRN para o cumprimento de sua missão organizacional recebe diariamente um fluxo estimado de 7.845 pessoas que consomem este recurso de forma significativa. No entanto, não foram constatados programas e medidas infraestruturais e operacionais, a fim de se evitar perdas e desperdícios do uso de água. Não existem ações sistemáticas para incentivar a redução do consumo e nem a utilização de técnicas de reuso e reciclagem da água, muito menos ações de manutenção preventiva da rede de distribuição.

As únicas iniciativas que merecem destaque são: o programa de qualificação e conscientização sobre o uso racional da água na irrigação de jardins e áreas verdes e o controle da qualidade da água dos bebedouros.

Também foi evidenciado que não existe captação e aproveitamento das águas pluviais. A fonte de abastecimento principal é um poço com 85 metros de profundidade localizado próximo ao centro de lazer da instituição. A água destinada aos bebedouros e torneiras das cozinhas da escola, a qual é ingerida por funcionários e alunos, é proveniente de um reservatório (com capacidade para 25 mil litros) que é abastecido pela rede pública de abastecimento (CAERN - Companhia de Águas e Esgotos do Rio Grande do Norte).

A captação própria através do poço atende a maior parte da demanda da Instituição, contudo, a instituição não possui outorga para uso conforme exigido pela Lei federal $n^{\circ}$ 9433/1997 que instituiu a Política Nacional de Recursos Hídricos. A ausência de registros de controle do volume de água consumido constitui um problema para o planejamento e monitoramento de programas de redução do consumo.

Atualmente, é apenas possível traçar um comparativo e estimar alguns valores: Segundo dados da FUNASA (2004) uma instituição de ensino consome cerca de 50l/hab.dia. Como o CEFET apresenta um fluxo de 7850 pessoas sugere-se um consumo estimado de 8.635 $\mathrm{m}^{3}$ /mês. Gerando um volume de esgoto na ordem de $6908 \mathrm{~m}^{3}$ /mês. O contrato com a CAERN só registra um consumo mensal de $62 \mathrm{~m}^{3}$ (R\$ 3 609,64) e um custo de $\mathrm{R} \$$ 2.526,55 por um volume de esgoto de $43,4 \mathrm{~m}^{3}$ /mês. Seria necessário um acompanhamento efetivo do volume de consumo da água do poço para estabelecer metas com base em indicadores confiáveis. 
Outros problemas também foram evidenciados como os vazamentos em alguns banheiros e nas torneiras e mangueiras do sistema de irrigação. A Caixa d’ água da Instituição não apresenta uma freqüência correta de limpeza - somente é limpa uma vez ao ano.

Em relação ao sistema de esgotamento sanitário da instituição, foi relatado que o esgoto gerado pela instituição é lançado na rede de coleta pública. Porém, a CAERN atualmente apenas realiza a coleta, não tratando o esgoto.

\section{Energia Elétrica}

Quanto ao uso de energia elétrica, destaca-se a existência de algumas ações para redução de consumo. Tais ações foram coordenadas pela Comissão de Energia do campus central do IFRN e contaram com a adesão de grande parte da comunidade local. Dentre as medidas destacam-se a substituição de parte das lâmpadas fluorescentes de $40 \mathrm{w}$ por $36 \mathrm{w}$ e dos reatores eletromagnéticos por eletrônicos. De forma gradativa, a instituição também está substituindo os condicionadores de ar do tipo “janela” por modelos mais eficientes.

A Comissão de Energia também coordenou o processo de manutenção das duas subestações da instituição e realizou um levantamento de carga de iluminação nos departamentos de Recursos Naturais, Construção Civil e Eletromecânica.

Para os próximos anos, um programa de controle e racionalização da energia está sendo elaborado e focalizará além das melhorias nas instalações e da redução da carga de consumo de todo sistema elétrico, os processos de conscientização dos usuários.

Faz-se necessário, o incentivo as mudanças de hábitos, pois, por exemplo, visitando as salas e corredores é comum se deparar com o desperdício de energia motivado pela prática de manter ou esquecer luzes acessas durante todo o dia. Ações sistemáticas de educação ambiental irão contribuir para estas mudanças.

O IFRN não conta com sistemas de energia alternativa para atender suas necessidades de consumo. Existe um projeto para estruturar a utilização de energia solar, porém, com uma ênfase mais didática e educacional.

\section{Programa de Gestão}

No IFRN, não foi evidenciado um histórico de auditoria ambiental, revisão ou avaliação ambiental da instituição. Os padrões de gerenciamento ambiental da ISO 14001 também não são seguidos, assim como não são utilizados indicadores ambientais para a avaliação do desenvolvimento geral da instituição. Nunca foi feito um diagnóstico dos impactos diretos ou significativos para o ambiente, e também não há provisão de recursos financeiros para implementação e operação de um Sistema de Gestão Ambiental (SGA). Não existe uma agenda 21 implementada, Entretanto existe uma comissão de gestão ambiental vinculada a direção geral e também são tomadas medidas de controle de acidentes no trabalho. 
Em setembro de 2007 o Programa de Educação Sanitária e Ambiental - PROGESA e a Comissão de Gestão Ambiental do IFRN promoveram o debate "Gestão Ambiental no IFRN: discussões em busca de soluções”. É importante destacar também a caracterização ambiental realizada pelo PROGESA através de observações em relação aos banheiros e bebedouros da instituição, bem como ao tratamento dado localmente ao lixo, à água e a vegetação. Este trabalho intitulado "Caracterização Ambiental do CEFET/RN: observações e reflexões” forneceu importantes subsídios para a elaboração da política ambiental.

No que se refere à Comissão de Gestão Ambiental, estão previstas ações de Auditoria Ambiental, Campanhas de Educação Ambiental, Gerenciamento de Resíduos Sólidos, Controle do Uso e Qualidade da Água, Implementação e Manutenção da Política Ambiental, Implementação de Novas Áreas Verdes e o Controle de Podas e Manejo do Bosque da Instituição.

\section{Requisitos Legais}

Quanto aos requisitos legais relacionados ao escopo ambiental, apenas é cumprido pela instituição o Alvará de Funcionamento. O IFRN não possui o devido Licenciamento Ambiental, apesar de ser exigido por alguns diplomas municipais como o código de obras e código do meio ambiente.

\section{Resíduos Sólidos}

Quanto ao gerenciamento de resíduos sólidos da instituição em tela, tem-se algumas considerações em relação ao acondicionamento e destinação final destes.

Foi identificado um programa de coleta seletiva, que apresenta falhas quanto à segregação, principalmente pela ausência de programas educacionais. Pelos relatos de um dos funcionários responsáveis pela seleção dos recicláveis, percebe-se que parte do lixo deixa de ser reciclado por não ter a disposição correta nas lixeiras da Instituição. De acordo com Macedo (2008) estudos realizados pelo programa de coleta seletiva apontam está realidade conforme demonstrado pela tabela 1 .

Tabela 1: Média das caracterizações físicas dos resíduos realizadas em 2005 e 2006

\begin{tabular}{c|c|c}
\hline \multirow{2}{*}{ PERCENTAGEM EM PESO (\%) } \\
\hline \multirow{2}{*}{ Material } & $\mathbf{2}$ Anos \\
\cline { 2 - 3 } & $\mathbf{2 0 0 5}$ & $\mathbf{2 0 0 6}$ \\
\hline Papel & 3,79 & 2,91 \\
\hline Metal & 0 & 0,51 \\
\hline Vidro & 0 & 0,41 \\
\hline Plástico & 5,45 & 3,31 \\
\hline Varrição & 14,93 & 14,88 \\
\hline Orgânico & 45,73 & 40,42 \\
\hline Rejeito & 30,1 & 37,56 \\
\hline Total & 100 & 100 \\
\hline
\end{tabular}


Fonte: MACEDO (2008).

A presença destes percentuais de materiais recicláveis no material enviado ao aterro revela que a coleta seletiva pode ser mais efetiva. O estudo evidenciou que a coleta dos recicláveis ainda não recolhe todo o material reciclável produzido nos pátios e nos laboratórios por não haver coletores específicos para os tipos de recicláveis gerados nesses locais e por problemas na triagem desse material. A quantidade de papel encontrado nos resíduos caracterizados indicou a falta de coletores específicos para o papel nas salas de aula e, também, a ausência de comprometimento dos funcionários em realizar a separação do papel dos demais resíduos nos setores geradores, onde existem coletores para papel, o que reflete a necessidade de um programa constante de conscientização ambiental com os funcionários. De acordo com o estudo os resíduos orgânicos foram os que apresentaram maior porcentagem em relação ao peso total, porém, são enviados ao aterro sanitário devido à inexistência de um funcionário, disponibilizado pela administração, para realizar a manutenção de um programa de compostagem que contemplasse esse tipo de resíduo e trouxesse alguns benefícios à instituição como a venda do composto ou sua utilização na horta e a diminuição do envio de resíduos ao aterro.

Não foi evidenciado um sistema de controle e registro de custos com reciclagem, recuperação e descarte de resíduos, assim como os funcionários não recebem tratamento especial para o manuseio de materiais perigosos.

Em relação ao destino dos resíduos sólidos, destaca-se que os resíduos comuns são coletados pela empresa de limpeza urbana, sendo que os recicláveis são comercializados. Vale enfatizar, que estes resíduos deveriam estar sendo destinado para associações e cooperativas dos catadores de materiais recicláveis, conforme o Decreto de Lei $n^{\circ} 5.940$ de 2006 que Instituiu a separação dos resíduos recicláveis descartados pelos órgãos e entidades da administração pública federal direta e indireta, na fonte geradora, e a sua destinação às associações e cooperativas dos catadores de materiais recicláveis, e dá outras providências.

Os resíduos perigosos são encaminhados para uma empresa de tratamento (SERQUIP). No entanto, vale ressaltar que a relação do IFRN com a SERQUIP não está respaldada por contrato entre as partes. Este é feito entre a SERQUIP e o laboratório de análises clínicas (Laboratório Privado), setor gerado de um grande volume de resíduos perigosos e terceirizado pela instituição.

Percebe-se também, que para um gerenciamento efetivo, ações concretas devem ser sistematizadas. Pensando nisso, a Comissão de Gestão Ambiental sugeriu a direção da Instituição a elaboração dos seguintes planos de gerenciamento - Resíduos do Serviço de Saúde, da lanchonete e restaurantes, dos laboratórios, dos setores administrativos e de aula e dos departamentos acadêmicos.

\section{Área Verde}

Em relação à vegetação do IFRN foi evidenciado um manejo satisfatório, principalmente, do ponto de vista estético. Todos os dias, as árvores e gramas existentes na instituição são aguadas - contudo deve-se repensar as estratégias utilizadas pela empresa terceirizada no 
que se refere ao horário e aos equipamentos utilizadas para dessa forma evitar o desperdício de água.

Os mesmo cuidados não são refletidos no bosque da Instituição que está em situação de abandono, servindo de descarte para o lixo e sendo alvo de podas irregulares e de ações de degradação. Entre os principais problemas destaca-se: ataque de ervas daninhas, falta de um plano de podas e de treinamento para a equipe responsável e o plantio de plantas exóticas do tipo NIN.

Em adição, não foi evidenciado a existência de programas de podas periódicos e com um controle técnico visando evitar a morte do vegetal.

\section{Proposição da Política Ambiental}

A política ambiental do IFRN foi elaborada com o objetivo de atender às prescrições da NBR ISO 14001, observando também às recomendações da Agenda 21, que sugere que “o ensino é também fundamental para conferir consciência ambiental e ética, valores e atitudes, técnicas e comportamentos em consonância com o desenvolvimento sustentável” (CONFERÊNCIA ..., 1992).

O procedimento adotado para estabelecer a política ambiental do IFRN foi pautado na gestão participativa - a política foi construída a partir da participação efetiva da comissão de meio ambiente e contempla sua visão de futuro sobre a gestão ambiental da instituição. Ela contém 08 diretrizes que tratam respectivamente de: Controle Eficiente de Água e Energia, Uso Racional de Materiais de Consumo, Gerenciamento de Resíduos sólidos, Gerenciamento das Obras Civis, Gerenciamento de Áreas Verdes, Educação Ambiental, Suporte de Recursos e Requisitos Legais.

A primeira diretriz estabelece a necessidade de se adotar procedimentos de controle e racionalização do uso de água e energia da instituição. Na avaliação ambiental inicial foi constatado que o IFRN já conta com ações nesse sentido - como o programa de qualificação e conscientização sobre o uso racional da água na irrigação de jardins e áreas verdes - contudo, acredita-se que a implementação de um sistema de gestão ambiental facilitará a integração das iniciativas existentes e evitará ações pontuais e isoladas.

A segunda diretriz estimula o uso racional de materiais de consumo e a minimização de desperdícios - percebe-se que a mudança de hábitos dos funcionários e alunos é fundamental para esse processo. Ressalta-se também a incorporação da exigência de critérios ambientais nos editais de licitação e de compra e aquisição de materiais e equipamentos utilizados na Instituição - tal iniciativa fortalece os fornecedores do IFRN e estimula a propagação das boas práticas ambientais.

Para o tópico Gerenciamento de Resíduos sólidos destaca-se o incentivo a minimização da geração de resíduos, a coleta seletiva e as práticas de reciclagem. Percebe-se que o gerenciamento dos resíduos produzidos pelas instituições de ensino e pesquisa não pode ser negligenciado. É importante destacar que a pretensão da Comissão de Gestão Ambiental de elaborar procedimento de gerenciamento dos Resíduos do Serviço de Saúde, da lanchonete e restaurantes, dos laboratórios, dos setores administrativos e de aula e dos 
departamentos acadêmicos, já denota conformidade com esta diretriz. Este tópico também pode estimular ações simples como a utilização de informes sobre os critérios de separação do lixo em locais estratégicos nas proximidades de cada lixeira.

Vale ressaltar também que o programa de gerenciamento de resíduos é exigido pela ANVISA (Agencia Nacional de Vigilância Sanitária), por meio da Resolução RDC $n^{\circ}$ 306/04, para todas as instituições que trabalham com ensino e pesquisa.

O quarto tópico aborda a necessidade de adequação das obras e reformas aos critérios ambientais, estimulando a utilização de tecnologias ambientais nos novos projetos tais como: eficiência energética, energias alternativas, reaproveitamento de água, coleta seletiva, etc.

A quinta diretriz estabelece a necessidade de adoção de práticas de implementação e manejo de áreas verdes, visando o ganho de qualidade ambiental. Atentando para essa diretriz a Comissão de Gestão Ambiental planeja o plantio de "Cercas Vivas", reflorestamento, retirada dos resíduos sólidos remanescentes da área do bosque, dentre outras ações.

Ao tratar da capacitação de recursos humanos, a lei $n^{0}$ 9795/99 determina a incorporação da dimensão ambiental na formação, especialização e atualização dos educadores e profissionais de todas as áreas do meio ambiente. A política ambiental procurou contemplar essa dimensão no sexto tópico - Educação Ambiental - orientando o desenvolvimento de processos de educação ambiental para sensibilizar alunos e servidores. Destaca-se também o estimulo a inserção das questões ambientais nas atividades de ensino, pesquisa e extensão.

Fornecer suporte de recursos para garantir a concretização das ações de gestão ambiental e cumprir os requisitos legais e demais requisitos aplicáveis e em vigência são as diretrizes que finalizam o texto da política.

Com a finalização do processo de elaboração e com a aprovação da política pela direção do IFRN se fez necessário o planejamento das estratégias de comunicação. A ISO 14001 não prescreve nenhuma forma de disseminação. Portanto, todo e qualquer recurso de divulgação pode ser utilizado pela instituição. No caso da unidade sede do IFRN, após a publicação da portaria $n^{0}$ 001/2008-DUS, uma circular foi elaborada e destinada a todos os setores e departamentos da Instituição. Cartazes foram fixados nos principais murais dos corredores e uma reportagem foi vinculada no endereço eletrônico da instituição.

É importante destacar que a ampla divulgação da Política contribui para a difusão das ações ambientais que serão compromisso dos gestores do IFRN. Inclusive, destaca-se uma das exigências da ISO 14001 que a política ambiental deve ser comunicada a todos que trabalhem em nome da organização além de ser disponibilizada ao público. Assim, foi no momento da aprovação da Política Ambiental está foi comunicada a todos os diretores de departamento, e estes ficaram responsabilizados em divulgas nos seus respectivos setores. Também foi recomendado que a política fosse divulgada na home-page institucional e em pontos estratégicos da organização.

No tocante ao atendimento da especificações do item 4.2 da ISO 14001, pode-se afirma que a política ambiental proposta está em conformidade com norma, principalmente 
atendendo aos itens de inclusão (melhoria contínua, prevenção da poluição e atendimento da legislação), além de estar apropriada com a natureza e escalas de impactos da instituição e fornecer uma estrutura para o estabelecimento de objetivos e metas. Vale destaca ainda que a sua forma de comunicação também está em conformidade.

Destaca-se ainda que a partir desta política ambiental, os outros requisitos do SGA devem ser implementados, principalmente o estabelecimento de instrumentos de controle do desempenho ambiental da instituição, como os objetivos, metas e programas ambientais e o estabelecimento de controle operacionais voltados para os aspectos significativos da instituição, bem como campanhas sistemáticas de educação ambiental. Desta forma, a instituição poderá atender aos compromissos assumidos pela política.

Para isso, sugere-se que inicialmente a organização priorize o tratamento dos pontos fracos identificados na avaliação inicial (gerenciar adequadamente os resíduos sólidos, reduzir os desperdícios de água e licenciar-se junto ao órgão ambiental competente). Em seguida, recomenda-se uma avaliação mais precisa dos aspectos e impactos ambientais e dos requisitos legais aplicáveis a estes, para que finalmente, sejam estabelecidos os objetivos, metas e programas ambientais.

\section{CONSIDERAÇÕES FINAIS}

Conclui-se com a realização deste trabalho que muitas ações, no contexto das Instituições de Ensino, podem ser implementadas na busca de uma gestão ambiental efetiva. No entanto, essas ações comprometem a melhoria contínua do desempenho ambiental quando implementadas de forma pontual e isolada.

É preciso estimular a parceria - juntando a iniciativa das instituições que querem melhor qualidade de vida com a ação dos órgãos públicos, das empresas, das comunidades. É necessário unir todo mundo na base do pensar globalmente e agir localmente - procurando passar do discurso para a ação e criando critérios e mecanismos confiáveis para avaliar quais ações são sustentáveis e quais não são. Nesse ponto de vista - o IFRN apresentou uma boa capacidade de articulação com as empresas com reflexos de destaque nas atividades de extensão que contemplam a temática ambiental.

A Avaliação Ambiental Inicial realizada para subsidiar a elaboração da Política Ambiental apontou os eixos-temáticos que passarão a nortear as ações e a definição de objetivos e metas e programas ambientais do IFRN, campus central.

É importante destacar que qualquer iniciativa para a inserção da temática ambiental nos cursos do IFRN deve considerar um diagnóstico do grau de sensibilização dos professores à questão, convidando-os a construir as reformas como um processo coletivo da instituição.

Há também de se desmistificar a relação Educação Ambiental versus Ecologia, para que cada profissional possa perceber o papel de sua profissão na questão. A estrutura rígida do ensino tradicional ainda reflete-se nas ações, que são tímidas quanto a integrações e à construção de projetos interdisciplinares. Por isso é urgente uma transformação na estrutura dos cursos da Instituição para que essas iniciativas sejam estimuladas. 
Espera-se que com as ações da Comissão de Gestão Ambiental e com as diretrizes da Política Ambiental a gestão ambiental extrapole as ações isoladas de algumas diretorias e englobe todos os departamentos da Instituição envolvendo professores e alunos.

\section{REFERÊNCIAS}

1. ASSOCIAÇÃO BRASILEIRA DE NORMAS TÉCNICAS. NBR ISO 14.001 Sistemas de gestão ambiental - Requisitos com orientação para uso: [Rio de Janeiro], 2004.

2. CAJAZEIRA, J. E. R. ISO 14.001 - Manual de implantação. Rio de Janeiro: Qualitymark ED., 1998.

3. CAPRA, F. O ponto de mutação. A ciência, a sociedade e a cultura emergente. $24^{\mathrm{a}}$ ed. SP. Editora Cultrix, 2003.

4. CONFERÊNCIA DAS NAÇÕES UNIDAS SOBRE O MEIO AMBIENTE E DESENVOLVIMENTO. Agenda 21. Rio de Janeiro, 1992.

5. FUNASA. Manual de saneamento. 3. ed. Brasília: Fundação Nacional de Saúde, 2004.

6. GIL, Antonio C. Como Elaborar Projetos de Pesquisa. 4. ed. São Paulo: Atlas, 2007.

7. LEFF, E. Pensar a complexidade ambiental. In: LEFF, E. (Org.). A complexidade ambiental. São Paulo: Cortez, 2003.

8. MACÊDO, R. G. Análise de indicadores do gerenciamento dos resíduos sólidos do CEFET/RN. Natal: CEFET/RN, 2008.

9. MOREIRA, M. S. Estratégia e implantação do sistema de gestão ambiental (Modelo Série ISO 14000). Belo Horizonte: Ed. DG, 2001.

10. MOURA, L. A. A. Qualidade e gestão ambiental, $3^{\circ}$ ed., São Paulo: Editora Juarez de Oliveira, 2002.

11. NALINI, J. R. Ética ambiental. 2 Ed. Campinas, SP. Millenium Editora Ltda., 2003.

12. REIS, M. J.L. ISO 14000: gerenciamento ambiental (um novo desafio para a sua competitividade) - Rio de Janeiro: Qualitymark, 1995.

13. ROESCH, Sylvia M. A. Projetos de estágio e de pesquisa em administração: guia para Estágios, Trabalhos de Conclusão, Dissertações e Estudos de Caso. 3. ed. São Paulo: Atlas, 2005.

14. SEIFFERT, M. E. B. ISO 14001 Sistemas de gestão ambiental: implantação objetiva e econômica. São Paulo: Atlas, 2007.

15. TAUCHEN, J. A.; BRANDILI, L. L. A gestão ambiental em Instituições de Ensino Superior: modelo para implementação em campos universitário. Disponível em: http://simpep.feb.unesp.br. Acesso em: 02 ago 2007.

16. TAUCHEN, J. A. Um modelo de gestão ambiental para implementação em instituições de ensino superior. Passo Fundo: UPF, 2006. 


\section{APÊNDICE - Política Ambiental do IFRN/Campus Central}

\section{CENTRO FEDERAL DE EDUCAÇÃO TECNOLÓGICA DO RIO GRANDE DO NORTE POLÍTICA AMBIENTAL - UNIDADE SEDE}

O IFRN, centro educacional de referência em ensino, pesquisa e extensão, ciente de que o meio ambiente, em todas as suas dimensões, constitui um elemento imprescindível à sobrevivência do Planeta Terra, considera relevante, dentro de sua função social, contribuir para o desenvolvimento sustentável do Estado do Rio Grande do Norte. Nesse sentido, busca praticar permanentemente aperfeiçoar a gestão ambiental, compreendendo-a como um processo dinâmico e evolutivo, visando assegurar a melhoria contínua de seu desempenho ambiental e prevenção da poluição. Assim sendo, compromete-se com as seguintes diretrizes:

\section{Controle Eficiente de Água e Energia}

- Adotar procedimentos de controle e racionalização do uso de água e energia da instituição.

\section{Uso Racional de Materiais de Consumo}

- Incentivar o uso racional e minimização de desperdícios;

- Exigir, nos editais de licitação de compra e aquisição de materiais e equipamentos, o cumprimento de padrões e regulamentações ambientais aplicáveis.

\section{Gerenciamento de Resíduos sólidos}

- Incentivar a minimização da geração de resíduos sólidos, a coleta seletiva e práticas de reciclagem.

Gerenciamento das Obras Civis 
- Garantir que as obras e reformas estejam adequadas à proteção do meio ambiente;

- Utilizar tecnologias ambientais nos novos projetos arquitetônicos e de engenharia (eficiência energética, energias alternativas, reaproveitamento de águas, coleta seletiva, entre outras).

\section{Gerenciamento de Áreas Verdes}

- Adotar práticas de implementação e manejo de áreas verdes, visando o ganho de qualidade ambiental.

\section{Educação Ambiental}

- Desenvolver processos de educação ambiental com alunos e servidores;

- Estimular a inserção das questões ambientais nas atividades de ensino, pesquisa e extensão.

\section{Suporte de Recursos}

- Prover recursos para garantir a concretização das ações de gestão ambiental.

\section{Requisitos Legais}

- Cumprir os requisitos legais e demais requisitos aplicáveis.

Enilson Araújo Pereira

Diretor - Campus Central 